\title{
Article \\ Predictors of Depressive Symptoms in Caregivers of Children with Attention-Deficit/Hyperactivity Disorder: A One-Year Follow-Up Study
}

\author{
Wen-Jiun Chou ${ }^{1,2}$, Ray C. Hsiao ${ }^{3,4}$, Chih-Cheng Chang ${ }^{5,6, *}$ and Cheng-Fang Yen $7,8,9, * \mathbb{D}$ \\ 1 Department of Child and Adolescent Psychiatry, Chang Gung Memorial Hospital, Kaohsiung Medical Center, \\ Kaohsiung 83301, Taiwan; wjchou@cgmh.org.tw \\ 2 College of Medicine, Chang Gung University, Taoyuan 33302, Taiwan \\ 3 Department of Psychiatry and Behavioral Sciences, University of Washington School of Medicine, \\ Seattle, WA 98195, USA; rhsiao@u.washington.edu \\ 4 Department of Psychiatry, Children's Hospital and Regional Medical Center, Seattle, WA 98105, USA \\ 5 Department of Psychiatry, Chi Mei Medical Center, Tainan 70246, Taiwan \\ 6 Department of Health Psychology, College of Health Sciences, Chang Jung Christian University, \\ Tainan 71101, Taiwan \\ 7 Department of Psychiatry, Kaohsiung Medical University Hospital, Kaohsiung 80708, Taiwan \\ 8 Department of Psychiatry, School of Medicine, Kaohsiung Medical University, Kaohsiung 80708, Taiwan \\ 9 College of Professional Studies, National Pingtung University of Science and Technology, \\ Pingtung 91201, Taiwan \\ * Correspondence: rabiata@mail.chimei.org.tw (C.-C.C.); chfaye@cc.kmu.edu.tw (C.-F.Y.); \\ Tel.: +886-6-2228116 (ext. 58604) (C.-C.C.); +886-7-3121101 (ext. 6816) (C.-F.Y.); \\ Fax: +886-6-2203702 (C.-C.C.); +886-7-3134761 (C.-F.Y.)
}

Citation: Chou, W.-J.; Hsiao, R.C.; Chang, C.-C.; Yen, C.-F. Predictors of Depressive Symptoms in Caregivers of Children with Attention-Deficit/ Hyperactivity Disorder: A One-Year Follow-Up Study. Int. J. Environ. Res. Public Health 2021, 18, 8835. https:// doi.org/10.3390/ijerph18168835

Academic Editors: Elena Commodari and Valentina Lucia La Rosa

Received: 8 July 2021

Accepted: 20 August 2021

Published: 22 August 2021

Publisher's Note: MDPI stays neutral with regard to jurisdictional claims in published maps and institutional affiliations.

Copyright: (c) 2021 by the authors Licensee MDPI, Basel, Switzerland This article is an open access article distributed under the terms and conditions of the Creative Commons Attribution (CC BY) license (https:// creativecommons.org/licenses/by/ $4.0 /)$.

\begin{abstract}
This 1-year follow-up study examined the predictive values of the demographics, depressive symptoms, stress-coping orientations, and perceived family support of caregivers as well as the internalizing, externalizing and ADHD symptoms of children with attention-deficit/hyperactivity disorder (ADHD) at baseline on the depressive symptoms of the caregivers after 1 year. A total of four hundred caregivers of children with ADHD were recruited. The baseline levels of the caregivers' depressive symptoms, stress-coping orientations, and perceived family support and the internalizing and externalizing problems of the children were assessed using the Center for Epidemiological Studies Depression Scale, the Coping Orientation to Problems Experienced, Family Adaptation, Partnership, Growth, Affection, Resolve Index, and the Child Behavior Checklist For Ages 6-18, respectively. Their predictions for the caregiver's depressive symptoms 1 year after the baseline were examined using linear regression analysis. In total, 382 caregivers of children with ADHD underwent the follow-up assessment 1 year from the baseline. A marital status of being separated or divorced, less effective coping and depressive symptoms orientation, and children with internalizing problems and ADHD symptoms at baseline were positively associated with the caregivers' depressive symptoms at follow-up, whereas the caregivers' perceived family support and an emotion-focused coping orientation at baseline were negatively associated with depressive symptoms at follow-up. Multiple characteristics of the caregivers and children with ADHD at baseline predicted the caregivers' depressive symptoms 1 year later.
\end{abstract}

Keywords: attention-deficit/hyperactivity disorder; behavioral problem; caregiver; depression; family support; predictor

\section{Introduction}

\subsection{Depression in Caregivers of Children with Attention-Deficit/Hyperactivity Disorder}

Depression is prevalent among caregivers of children with attention-deficit/hyperactivity disorder (ADHD) [1-4]. The negative effects of caregiver depression on children with 
ADHD have been well established. Follow-up studies have revealed that caregiver depression predicts the exacerbation or persistence of ADHD symptoms [5], conduct disorder symptoms [6,7], and oppositional defiant disorder symptoms [8] in children with ADHD. In addition, studies have reported an association of caregiver depression with dysfunctional parenting skills (e.g., imposing corporal punishment) [9], nonoptimal reinforcement [10], lack of or overly strict disciplining [11,12], and low sensitivity and warmth during interactions with children with ADHD [11,13,14]. Moreover, studies have found that targeting parental depression may enhance the effects of behavioral interventions on the parenting skills of caregivers and the oppositional and noncompliant behaviors of children [15]. Therefore, screening for depressive symptoms and administering interventions targeting depression among the caregivers of children with ADHD are crucial in clinical practice $[6,16]$.

\subsection{Factors Predicting Caregivers' Depressive Symptoms}

The determination of factors that predict caregiver depressive symptoms is essential for developing prevention and intervention programs for the caregivers of children with ADHD. Previous studies have demonstrated the cross-sectional association of caregiver depression with several caregiver- and child-related factors. Caregiver factors include being female [16], low income [4], not living with their partner [17], and being the only caregiver in the family [4]. Child factors include ADHD symptoms [16], hyperactive/impulsive, and combined types of ADHD were significant predictors of depression [4], internalizing problems such as depression and anxiety [18], and externalizing problems [19]. However, no prospective study has examined the predictors of depressive symptoms in the caregivers of children with ADHD.

\subsection{Prediction for Depressive Symptoms in Caregivers Based on Their Stress-Coping Orientations}

The caregivers of children with ADHD experience considerable parenting stress [20] and courtesy stigma [21]. Stress-coping strategies adopted by caregivers to cope with stress and the effectiveness of these strategies may affect the mental health of caregivers. Problemsolving, emotion-focused, and less effective strategies are the three most commonly used stress-coping orientations [22-25]. Problem-focused coping constitutes actively modifying or eliminating sources of stress to manage stressful situations [22,23]. Emotion-focused coping involves exerting regulative efforts to diminish the emotional consequences of stressful events $[22,23]$. Less effective coping strategies include behavioral and mental disengagement to avoid directly dealing with stressful situations [23]. A cross-sectional study including the mothers of children with intellectual disabilities reported that the adoption of problem-coping strategies was associated with higher positive affect, whereas active-avoidance coping was associated with higher negative affect and increased anxiety and depression [26]. However, no prospective study has examined whether various stress-coping orientations can predict depressive symptoms in the caregivers of children with ADHD. If stress-coping orientations can predict depressive symptoms in caregivers, then effective problem-solving strategies should be included in programs designed for improving caregiver mental health.

\subsection{Prediction for Depressive Symptoms in Caregivers Based on Internalizing and Externalizing} Problems of Children with ADHD

Internalizing (e.g., depressive, anxiety, and somatic symptoms) and externalizing (e.g., oppositional defiance and conduct problems) symptoms are prevalent in children with ADHD [27-32]. A prospective study found that the parents of children with ADHD and internalizing and externalizing comorbidities reported poorer family quality of life than the parents of children with ADHD alone did [33]. Additional prospective studies examining whether the internalizing and externalizing symptoms of children with ADHD can predict caregiver depressive symptoms may provide evidence for the effects of caregiver depressive symptoms on the comorbid behavioral problems of children with ADHD. 


\subsection{Prediction for Depressive Symptoms in Caregivers Based on Perceived Family Support and Marriage Status}

Family support is a microsystemic factor [34] that may help caregivers of children with ADHD maintain their mental health [35-37]. Additional prospective studies should examine whether the protective effects of family support still exist when other microsystemic factors (e.g., children's internalizing and externalizing problems) and individual factors (e.g., caregiver stress-coping orientations) are considered together. Research has found that parents of children with ADHD are more likely to divorce compared to those of children without ADHD [38], and divorce can also cause health-related immune alterations and increase the risk of depressive problems [39]. Whether a marriage status of separation or divorce can predict caregivers' depressive problems warrants further study.

\subsection{Persistent Depressive Symptoms in Caregivers of Children with ADHD}

Research has found that caregivers of children with ADHD had heavy care burdens [40-42] and high parenting stress [43,44]. Caregivers might also experience public stigma toward ADHD [45] and have affiliate stigma toward themselves, which may further increase their psychological distress [46] and the risk of depressive problems [47]. It is reasonable to hypothesize that caregiver depressive symptoms may persist or even worsen during the growth stages of children with ADHD; therefore, depressive symptoms at baseline may predict the non-remitted depressive symptoms at follow-up. However, whether this predictive effect exists warrants further study.

\subsection{Aims of This Study}

This prospective study followed the participants of the Study on Affiliate Stigma in Caregivers of Children with ADHD [47] 1 year after the initial study. In the previous analysis, we found that the affiliate stigma that the caregivers feel towards themselves at baseline positively predicted their children's affective and somatic problems 1 year later, after controlling for the caregivers' depressive symptoms and children's behavioral problems at baseline [48]. In the present study, we examined the predictive values of the demographics (gender, age, education level, and marriage status), depressive symptoms, stress-coping orientations and perceived family support of caregivers and the demographics (gender and age), ADHD symptoms, and internalizing and externalizing problems of children with ADHD at baseline the depressive symptoms of the caregivers after 1 year. We hypothesized that the demographics, depressive symptoms, perceived family support, and various stress-coping orientations of the caregivers at baseline could predict the caregivers' depressive symptoms at follow-up. Moreover, ADHD symptoms and internalizing and externalizing problems of children with ADHD at baseline could predict caregivers' depressive symptoms at follow-up.

\section{Methods}

\subsection{Participants and Procedures}

The procedure used for recruiting participants at baseline in the Study on Affiliated Stigma in Caregivers of Children with ADHD was described elsewhere [47]. In brief, 400 caregivers of children aged between 6 and 18 years diagnosed as having ADHD according to the criteria of the Diagnostic and Statistical Manual of Mental Disorders, Fifth Edition [49] were recruited from the child and adolescent psychiatric outpatient clinics of two medical centers in Kaohsiung, Taiwan. Caregivers' depression, stress-coping orientations, and perceived family support as well as their children's ADHD and internalizing and externalizing problems were assessed. These caregivers of children with ADHD were contacted at outpatient clinics 1 year later and were invited to undergo the follow-up assessment.

The Institutional Review Boards of Kaohsiung Chang Gung Memorial Hospital (approval number: 202000605A3; date of approval: 15 May 2020) and Kaohsiung Medical University Hospital (approval number: KMUHIRB-E(I)-20200111; date of approval: 1 
June 2020) approved the study. All participants provided written informed consent before undergoing the assessment.

\subsection{Measures}

\subsubsection{Depressive Symptoms}

The 20-item Mandarin Chinese version of the Center for Epidemiological StudyDepression Scale (CES-D) was used to assess the severity of depressive symptoms in the caregivers at baseline and at follow-up [50,51]. Caregivers were asked how often they experienced each depressive symptom in the preceding month. The response categories were (0) rarely or none of the time (less than 1 day), (1) some or a little of the time (1-2 days), (2) occasionally or a moderate amount of the time (3-4 days), or (3) most or all of the time (5-7 days). A higher total score indicates more severe depressive symptoms. Cronbach's $\alpha$ for the scale in the present study was 0.88 . A CES-D cutoff of $\geq 21$ was used to identify individuals with a high level of depressive symptom [52].

\subsubsection{Stress-Coping Orientations}

The 53-item Coping Orientation to Problems Experienced (COPE) evaluation was used to assess the caregivers' stress-coping orientations at baseline. The COPE measured three domains of coping orientations: problem-focused coping, emotion-focused coping, and less effective coping [23,53]. Every item was rated on a 4-point Likert scale ranging from 1 (usually don't do this at all) to 4 (usually do this a lot). A higher total score for a particular domain indicates that participants are more likely to cope with stress by using that strategy. Cronbach's $\alpha$ for the three domains in the scale in the present study ranged from 0.68 to 0.78 .

\subsubsection{Perceived Family Support}

The five-item Mandarin Chinese version of the Family Adaptation, Partnership, Growth, Affection, Resolve (APGAR) Index was used to examine the caregivers' perceived family support at baseline [54,55]. Every item was rated on a 4-point Likert scale ranging from 1 (never) to 4 (always). A higher total score represents a higher level of perceived family support. Cronbach's $\alpha$ for the scale in the present study was 0.82 .

\subsubsection{Children's Internalizing and Externalizing Problems and ADHD Symptoms}

The caregiver-reported Chinese Version of the Child Behavior Checklist for Ages 6-18 (CBCL/6-18) was used to measure the children's behavioral problems at baseline [56,57]. We used the recommended T-score transformations of the raw behavior scores that were adjusted for age and sex differences in behavior found in normative samples. We used the domains of internalizing and externalizing problems and ADHD symptoms for analysis. Because the CBCL / 6-18 defined those with a T score higher than 70 (two standard deviation of the mean) as having severe symptoms [56,57], we used a cutoff of $>70$ to identify children with severe symptoms.

\subsubsection{Demographic Characteristics}

The caregivers' sex, age, and marital status, and the children's sex, and age were collected at baseline. We also determined the caregivers' total length of education by calculating their total years of receiving formal education.

\subsection{Statistical Analysis}

Data analysis was performed using SPSS 24.0 (SPSS, Chicago, IL, USA). The variables examined in the present study were presented as percentages, means, and standard deviations (SD). We used skewness and kurtosis to examine whether the continuous variables were normally distributed. According to Kim [58], the absolute skewness values $<2$ and kurtosis values $<7$ indicate normal distribution if the sample size was larger than 300 . The predictive effects of the caregivers' demographic characteristics, depressive symptoms at 
baseline, perceived family support, and orientations of stress-coping strategies and the children's demographic characteristics and behavioral problems and ADHD symptoms (independent variables) on the caregivers' depressive symptoms at follow-up (dependent variable) were first examined using univariate linear regression analysis. Predictors that were significantly associated with depressive symptoms in univariate linear regression further entered into a backward selection of multivariate linear regression analysis. A two-tailed $p$ value of $<0.05$ was used to present statistical significance. We used tolerance, variance inflation factor (VIF), and a condition index to examine the multicollinearity of the multiple regression analysis. A value of $\leq 0.1$ for tolerance, $>2.5$ for VIF, and $>30$ for the condition index indicate concern for multicollinearity among variables [59]. The Durbin Watson statistic was used test the autocorrelation in the residuals.

\section{Results}

In total, 382 (95.5\%, 308 female and 74 male) caregivers of children with ADHD underwent the follow-up assessment 1 year later. No difference in the caregivers' $\operatorname{sex}\left(\chi^{2}=0.766\right.$, $p=0.381)$, marital status $\left(\chi^{2}=1.998, p=0.158\right)$, age $(t=0.475, p=0.635)$, educational level $(t=-1.325, p=0.186)$, CES-D scores $(t=-0.271, p=0.787)$, perceived family support $(t=-0.384, p=0.701)$, or stress-coping orientations $(t=-1.214$ to $-0.204, p=0.225-0.838)$ nor any difference in the children's sex $\left(\chi^{2}=0.845, p=0.358\right)$, age $(t=-0.903, p=0.367)$, or behavioral problems $(t=-1.121$ to $-0.672, p=0.263-0.502)$ were found between caregivers who participated at baseline and who did not undergo the follow-up assessment.

Table 1 lists the caregivers' depressive symptoms at baseline and follow-up; the caregivers' demographic characteristics, perceived family support, and stress-coping orientations at baseline; and the children's demographic characteristics, behavioral, and ADHD problems at baseline. In total, $83(21.7 \%)$ and $89(23.3 \%)$ caregivers reported a high level of depressive symptoms at baseline and at-follow-up, respectively. Of the 83 caregivers with a high level of depressive symptoms at baseline, $55(66.3 \%)$ still had a high level of depressive symptoms at follow-up. Of the 299 caregivers with a low level of depressive symptoms at baseline, $34(11.4 \%)$ turned to report a high level of depressive symptoms at follow-up. Based on the scores of the $\mathrm{CBCL} / 6-18$, the proportions of children with severe internalizing, externalizing, and ADHD symptoms were $13.1 \%, 17.3 \%$, and $21.7 \%$, respectively. The absolute skewness values of the continuous variables ranged from 0.101 to 1.034; the absolute kurtosis values ranged from 0.014 to 1.170 . The skewness and kurtosis values indicated that the continuous variables were normally distributed.

Table 2 presents the results of the univariate linear regression examining the associations of the caregivers' and children's factors at baseline with the caregivers' depressive symptoms at follow-up. Regarding the caregiver factors, the results indicate that compared to the caregivers who were married or who cohabited at baseline, the caregivers who were separated or divorced had greater depressive symptoms at follow-up. Depressive symptoms at baseline and the orientation of less effective coping were positively associated with depressive symptoms at follow-up, whereas perceived family support and the problem-focused coping and emotion-focused coping orientations were negatively associated with depressive symptoms at follow-up. Regarding child factors, internalizing and externalizing problems and ADHD symptoms were positively associated with the caregivers' depressive symptoms at follow-up. 
Table 1. Caregivers' demographics, depressive symptoms, perceived family support, stress-coping orientation and children's demographics, behavioral, and ADHD symptoms $(n=382)$.

\begin{tabular}{|c|c|c|c|}
\hline Variable & $n(\%)$ & Mean (SD) & Range \\
\hline \multicolumn{4}{|l|}{ Caregivers' characteristics } \\
\hline Depressive symptoms at baseline & & $14.4(9.9)$ & $0-55$ \\
\hline \multicolumn{4}{|c|}{ Level of depressive symptoms at baseline } \\
\hline Low & $299(78.3)$ & & \\
\hline High & $83(21.7)$ & & \\
\hline Depressive symptoms at follow-up & & $13.8(9.6)$ & $0-45$ \\
\hline \multicolumn{4}{|c|}{ Level of depressive symptoms at follow-up } \\
\hline Low & $293(76.7)$ & & \\
\hline High & $89(23.3)$ & & \\
\hline \multicolumn{4}{|l|}{ Gender } \\
\hline Female & $308(80.6)$ & & \\
\hline Male & $74(19.4)$ & & \\
\hline Age (years) & & $43.1(7.0)$ & $23-69$ \\
\hline Length of education (years) & & $14.2(3.2)$ & $0-28$ \\
\hline \multicolumn{4}{|l|}{ Marriage status } \\
\hline Married or cohabited & $307(80.4)$ & & \\
\hline Separated or divorced & $75(19.6)$ & & \\
\hline Perceived family support & & $15.8(3.3)$ & $6-20$ \\
\hline Problem-focused coping orientation & & $62.0(11.4)$ & $20-80$ \\
\hline Emotion-focused coping orientation & & $50.9(8.3)$ & $20-77$ \\
\hline Less effective coping orientation & & $23.6(5.6)$ & $12-44$ \\
\hline \multicolumn{4}{|l|}{ Children's characteristics } \\
\hline \multicolumn{4}{|l|}{ Gender } \\
\hline Girl & $76(19.9)$ & & \\
\hline Boy & $306(80.1)$ & & \\
\hline Age (years) & & $10.9(3.2)$ & $6-18$ \\
\hline Internalizing problems & & $60.3(10.3)$ & $33-87$ \\
\hline \multicolumn{4}{|l|}{ Severe internalizing problems } \\
\hline No & $332(86.9)$ & & \\
\hline Yes & $50(13.1)$ & & \\
\hline Externalizing problems & & $59.8(10.5)$ & $33-84$ \\
\hline \multicolumn{4}{|l|}{ Severe Externalizing problems } \\
\hline No & $316(82.7)$ & & \\
\hline Yes & $66(17.3)$ & & \\
\hline ADHD symptoms & & $64.1(7.7)$ & $50-80$ \\
\hline \multicolumn{4}{|l|}{ Severe ADHD symptoms } \\
\hline No & $299(78.3)$ & & \\
\hline Yes & $83(21.7)$ & & \\
\hline
\end{tabular}

Factors that were significantly associated with the caregivers' depressive symptoms in univariate linear regression analysis were selected into a backward selection of multivariate linear regression analysis to examine their association with the caregivers' depressive symptoms at follow-up (Table 3). The results of Model 1 demonstrated that a marital status of being separated or divorced and a less effective coping orientation as well as the children with internalizing problems and ADHD symptoms at baseline were positively associated with the caregivers' depressive symptoms at follow-up, whereas the caregivers' perceived family support and an emotion-focused coping orientation at baseline were negatively associated with depressive symptoms at follow-up. The caregivers' depressive symptoms at baseline were further selected into multivariate linear regression analysis. The results of Model 2 indicate that depressive symptoms at baseline were significantly associated with depressive symptoms at follow-up in the caregivers. Multicollinearity among the variables was not detected because the tolerance and VIF values ranged from 0.758 to 0.988 and from 1.012 to 1.319 , respectively, and the condition index value was 26.976 . The value of the Durbin Watson statistic was 1.974, indicating a weak autocorrelation in the residuals. 
Table 2. Predictors of depressive symptoms at follow-up in caregivers of children with ADHD: univariate regression analysis.

\begin{tabular}{lcc}
\hline \multirow{2}{*}{ Variable } & \multicolumn{2}{c}{ Depressive Symptoms at Follow-Up } \\
\cline { 2 - 3 } & B (SE) & $\mathbf{9 5 \% ~ C I ~}$ \\
\hline Caregiver & & \\
Male a $^{\mathrm{a}}$ Age & $-2.182(1.277)$ & $-4.693-0.328$ \\
Education & $-0.070(0.072)$ & $-0.212-0.072$ \\
Marriage status of separation or divorce & $-0.206(0.160)$ & $-0.521-0.109$ \\
Depressive symptoms at baseline & $3.142(1.265)^{*}$ & $0.654-5.630$ \\
Perceived family support & $0.714(0.038)^{* * *}$ & $0.638-0.789$ \\
Problem-focused coping & $-1.008(0.146)^{* * *}$ & $-1.296--0.720$ \\
Emotion-focused coping & $-0.158(0.044)^{* * *}$ & $-0.244--0.072$ \\
Less effective coping & $-0.127(0.060)^{*}$ & $-0.246--0.008$ \\
Children's characteristics & $0.623(0.086)^{* * *}$ & $0.455-0.791$ \\
Boy c & & \\
Age & $0.378(1.269)$ & $-2.117-2.874$ \\
Internalizing problems & $-0.149(0.157)$ & $-0.459-0.160$ \\
Externalizing problems & $0.348(0.046)^{* * *}$ & $0.258-0.438$ \\
ADHD symptoms & $0.260(0.047)^{* * * *}$ & $0.169-0.352$ \\
\hline ADHD: & $0.356(0.063)^{* * *}$ & $0.232-0.480$ \\
\hline
\end{tabular}

ADHD: attention-deficit/hyperactivity. ${ }^{\text {a }}$ Female as the reference; ${ }^{b}$ marriage status of being married or cohabited as the reference; ${ }^{c}$ girl child as the reference. ${ }^{*}: p<0.05 ;{ }^{* * *} p<0.001$.

Table 3. Predictors of depressive symptoms at follow-up: multivariate regression analysis.

\begin{tabular}{|c|c|c|c|c|}
\hline \multirow{3}{*}{ Variable } & \multicolumn{4}{|c|}{ Depressive Symptoms at Follow-Up } \\
\hline & \multicolumn{2}{|c|}{ Model 1} & \multicolumn{2}{|c|}{ Model 2} \\
\hline & B (SE) & $95 \% \mathrm{CI}$ & B (SE) & $95 \% \mathrm{CI}$ \\
\hline Caregivers' marital status of separation or divorce ${ }^{a}$ & $2.215(1.092) *$ & $0.067-4.364$ & $2.045(0.899) *$ & $0.988-1.012$ \\
\hline Caregivers' perceived family support & $-0.539(0.145)^{* * *}$ & $-0.823--0.255$ & & \\
\hline Caregivers' emotion-focused coping & $-0.180(0.057) * *$ & $-0.292--0.067$ & & \\
\hline Caregivers' less effective coping & $0.549(0.086)^{* * *}$ & $0.380-0.717$ & $0.144(0.070) *$ & $0.833-1.200$ \\
\hline Children's internalizing problems & $0.192(0.047)^{* * *}$ & $0.100-0.284$ & $0.088(0.040)^{*}$ & $0.758-1.319$ \\
\hline Children's ADHD symptoms & $0.138(0.061) *$ & $0.067-4.364$ & $0.120(0.050) *$ & $0.831-1.204$ \\
\hline Caregivers' depressive symptoms at baseline & & & $0.621(0.042)^{* * *}$ & $0.779-1.284$ \\
\hline
\end{tabular}

ADHD: attention-deficit/hyperactivity. ${ }^{a}$ Marriage status of being married or cohabited as the reference. ${ }^{*}: p<0.05 ;{ }^{* *}: p<0.01$; ***: $p<0.001$.

\section{Discussion}

The results of this study indicate that over one-fifth of the caregivers had a high level of depressive symptoms. Multiple characteristics of the caregivers, namely marital status, perceived family support, emotion-focused and less effective coping strategy orientations, and depressive symptoms at baseline and characteristics of children with ADHD, namely internalizing problems and ADHD symptoms at baseline predicted the caregivers' depressive symptoms 1 year later. The results indicated that the mental health of caregivers can be affected by both individual and environmental factors.

\subsection{Caregivers' Depressive Symptoms}

The results of the present study reveal that $21.7 \%$ and $23.3 \%$ of the caregivers reported a high level of depressive symptoms at baseline and at follow-up, respectively. Moreover, nearly two-thirds $(66.3 \%)$ of caregivers reported non-remitted depressive symptoms in the 1-year follow-up period. Depressive symptoms at baseline had the most powerful predictive effect on depressive symptoms at follow-up. Parental depressive disorders increase the risk of offspring ADHD [18,60,61]; the high comorbidity of parental depressive disorders and child ADHD can be the biological result of familial aggregation. Because of the negative effects of depressive problems on the health of caregivers and children with 
ADHD, depressive symptoms in the caregivers of children with ADHD warrants early identification and intervention. Caregivers with depressive symptoms require individual treatment or expanded parenting intervention targeting their cognition [62]. Intervention programs designed to alleviate depressive problems that caregivers may face can also be beneficial for the children who these caregivers take care of [63].

\subsection{Caregivers' Perceived Family Support and Marital Status}

The results of the present study show that the caregivers' perception of having low family support at baseline predicted depressive symptoms 1 year later. Congruent with the results of previous studies [35-37], the results of this study also supported that family support is a factor [34] that may help caregivers of children with ADHD maintain their mental health. The present study also found that a marital status of being separated or divorced at baseline predicted depressive symptoms 1 year later. Divorce can not only cause health-related immune alterations and increase the risk of depression [39] but can also result in a lack of a coadjutant to manage the behaviors of children with ADHD, thus increasing the caregivers' parental distress. A previous study on the parents of children with psychopathology found that parents who did not live together had a higher level of depression than did those who lived together [17]. The results of this study indicated that enhancing family support, especially for caregivers who are separated or divorced, is important to improve caregiver mood regulation.

\subsection{Caregivers' Stress-Coping Orientations}

Coping refers to the process of managing psychological stress through cognitive or behavioral efforts [64]. The results of the present study showed that the caregivers' adoption of less effective coping mechanisms at baseline increased the risk of depressive symptoms at follow-up. Less effective coping strategies measured in the COPE include behavioral and mental disengagement [23]. Behavioral disengagement is a coping strategy in which an individual reduces their effort to deal with a stressor [23]. The caregivers of children with ADHD may experience the difficult position of being unable to effectively change their children's behaviors despite all efforts; this may result in learned helplessness [19]. People in a state of helplessness tend to adopt behavioral disengagement as a strategy to cope with stress [23]. Mental disengagement is a coping strategy in which individuals attempt to distract themselves from thinking about the behavioral dimension or goal with which the stressor is interfering [23]. Caregivers who adopt mental disengagement as a coping strategy may engage in alternative activities to take their minds off parenting difficulties or escape through sleep or by spending too much time watching television or using the Internet. Adoption of less effective coping strategies such as behavioral and mental disengagement often impedes the development of adaptive coping [65] and thus increases the risk of psychological distress and depression [66]. This study demonstrated that caregivers with emotion-focused coping orientations at baseline were negatively associated with depressive symptoms at follow-up. Parents may experience multiple sources of stress when taking care of children with ADHD such as managing their children's behaviors, supervising the completion of their children's daily routines, maintaining relationships among family members, and craving social support [35]. Emotion-focused coping such as seeking socioemotional support, positive reinterpretation, acceptance of stressors, and perceived growth in the process of managing stress may diminish the negative emotional consequences of stressful events $[22,23]$. The results of this study indicate that mental health professionals must help the caregivers of children with ADHD to develop effective stress-coping strategies but not avoidance or disengagement strategies to reduce the risk of depression.

\subsection{Children's ADHD Symptoms and Internalizing Problems}

The proportions of children with severe internalizing, externalizing, and ADHD symptoms determined by the cutoff of a T score $>70$ (2 SD) on the CBCL/6-18 were $13.1 \%, 17.3 \%$ 
and $21.7 \%$, respectively, in this study. Because only about $2.3 \%$ of the children in the general population have a T score $>70$ on the CBCL/6-18 $[56,57,67]$, the proportions of children with severe internalizing, externalizing, and ADHD symptoms in this study were high. Congruent with our hypothesis and the results of a cross-sectional study [16], our study results demonstrate that the level of children's ADHD symptoms at baseline increased the risk of depressive symptoms in caregivers 1 year later. ADHD symptoms significantly relate to impairment in peer, child-parent, and student-teacher relationships [68-71]. Moreover, children with ADHD are prone to accidental injury and trauma [72,73] and have higher mortality [74] than those without ADHD. All of the adverse consequences of ADHD increase the caregivers' burden of care and psychological distress and may contribute to their depression. Previous studies have revealed that the treatment of children with ADHD exerts a favorable effect on their caregivers' depressive symptoms [75,76].

A cross-sectional study revealed that the total behavioral problems of children with ADHD, as determined using the CBCL, were related to caregiver depressive symptoms [19]. However, the findings of the present study indicate that children's internalizing but not externalizing problems at baseline predicted caregiver depressive symptoms 1 year later. ADHD and internalizing problems, such as anxiety and depression, are correlated in families [18]. The prediction of the caregivers' depressive symptoms based on their children's internalizing problems may be the result of familial aggregation. Moreover, compared to individuals with ADHD but no significant internalizing problems, those with comorbid ADHD and significant internalizing problems had poorer neurocognitive function [77], poorer psychosocial functioning [78,79], and a lower response rate to stimulant treatment [80]. These adverse consequences of comorbid internalizing problems may increase caregiver stress and worsen depressive symptoms.

\subsection{Strengths and Limitations}

This is one of the first prospective studies to examine the predictive values of stresscoping orientations and perceived family support in caregivers and the behavioral problems of children with ADHD on the depressive symptoms of caregivers of children with ADHD. The present study identified several modifiable predictors of caregiver depressive symptoms and provided evidence to develop prevention programs for reducing the risk of depressive symptoms in caregivers of children with ADHD. However, the present study has several limitations. First, this study only collected reports from caregivers. Commonmethod variance might occur due to the use of a single data source. Second, whether caregivers received pharmacological or psychological treatment for their depressive symptoms was not determined in this study. Treatment might affect the association between potential predictors at baseline and depressive symptoms at follow-up. We also did not collect the data regarding the treatment for the children's ADHD at follow-up. Moreover, we did not determine the history of depressive disorders and treatment in caregivers with depressive symptoms. A long history of depressive disorders and a lack of treatment may have deleterious effects on caregiver-child interaction and the recovery of the caregivers' depressive symptoms. Third, this study examined the predictive values of caregiver stresscoping orientations and perceived family support and the effect of children's internalizing and externalizing problems on the depressive symptoms of caregivers. The predictive values of other individual and environmental factors warrant further study.

\section{Conclusions}

The present study results indicated that mental health can be affected by both individual and environmental factors among the caregivers of children with ADHD. These predictors should be considered while developing prevention and intervention programs for the depressive symptoms that may be experienced by caregivers. Because the depressive symptoms experienced by caregivers may not remit spontaneously, mental health professionals should routinely survey and provide necessary treatment for depressive symptoms experienced by caregivers. Helping caregivers to develop effective stress-coping 
strategies and treating children's ADHD and internalizing behavioral problems may promote caregiver mental health. In addition, mental health professionals should enhance psychosocial support for the caregivers of children with ADHD to prevent the development of depressive symptoms.

Author Contributions: W.-J.C. conducted the study and drafted the manuscript. R.C.H. revised the manuscript. C.-C.C. analyzed the data. C.-F.Y. formulated the goals of study. All authors have read and agreed to the published version of the manuscript.

Funding: This study was supported by grants awarded by the Chi Mei Medical Center and the Kaohsiung Medical University Research Foundation (109CM-KMU-009). The funding agencies did not have a role in this study.

Institutional Review Board Statement: The institutional review boards of Kaohsiung Chang Gung Memorial Hospital (approval number: 202000605A3; date of approval: 15 May 2020) and Kaohsiung Medical University Hospital (approval number: KMUHIRB-SV(I)-20190130 and KMUHIRB-E(I)20200111; date of approval: 7 May 2019 and 1 June 2020) approved this study.

Informed Consent Statement: All participants provided written informed consent.

Data Availability Statement: The data will be available upon reasonable request to the corresponding authors.

Conflicts of Interest: The authors declare no conflict of interest.

\section{References}

1. Chi, T.C.; Hinshaw, S.P. Mother-child relationships of children with ADHD: The role of maternal depressive symptoms and depression-related distortions. J. Abnorm. Child. Psychol. 2002, 30, 387-400. [CrossRef]

2. Chronis, A.M.; Lahey, B.B.; Pelham, W.E., Jr.; Kipp, H.L.; Baumann, B.L.; Lee, S.S. Psychopathology and substance abuse in parents of young children with attention-deficit/hyperactivity disorder. J. Am. Acad. Child. Adolesc. Psychiatry 2003, 42, 1424-1432. [CrossRef] [PubMed]

3. Lesesne, C.A.; Visser, S.N.; White, C.P. Attention-deficit/hyperactivity disorder in school-aged children: Association with maternal mental health and use of health care resources. Pediatrics 2003, 111, 1232-1237. [PubMed]

4. Al-Balushi, N.; Al Shekaili, M.; Al-Alawi, M.; Al-Balushi, M.; Panchatcharam, S.M.; Al-Adawi, S. Prevalence and predictors of depressive symptoms among caregivers of children with attention-deficit/hyperactivity disorder attending a tertiary care facility: A cross-sectional analytical study from Muscat, Oman. Early Child. Dev. Care. 2019, 189, 1515-1524. [CrossRef]

5. Walls, M.; Cabral, H.; Feinberg, E.; Silverstein, M. Association between changes in caregiver depressive symptoms and child attention-deficit/hyperactivity disorder symptoms. J. Dev. Behav. Pediatr. 2018, 39, 387-394. [CrossRef]

6. Agha, S.S.; Zammit, S.; Thapar, A.; Langley, K. Maternal psychopathology and offspring clinical outcome: A four-year follow-up of boys with ADHD. Eur. Child. Adolesc. Psychiatry 2017, 26, 253-262. [CrossRef] [PubMed]

7. Chronis, A.M.; Lahey, B.B.; Pelham, W.E., Jr;; Williams, S.H.; Baumann, B.L.; Kipp, H.; Jones, H.A.; Rathouz, P.J. Maternal depression and early positive parenting predict future conduct problems in young children with attention-deficit/hyperactivity disorder. Dev. Psychol. 2007, 43, 70-82. [CrossRef]

8. Brammer, W.A.; Galán, C.A.; Mesri, B.; Lee, S.S. Parental ADHD and depression: Time-varying prediction of offspring externalizing psychopathology. J. Clin. Child. Adolesc. Psychol. 2018, 47, S137-S149. [CrossRef]

9. Shin, D.W.; Stein, M.A. Maternal depression predicts maternal use of corporal punishment in children with attentiondeficit/hyperactivity disorder. Yonsei Med. J. 2008, 49, 573-580. [CrossRef]

10. Thomas, S.R.; O'Brien, K.A.; Clarke, T.L.; Liu, Y.; Chronis-Tuscano, A. Maternal depression history moderates parenting responses to compliant and noncompliant behaviors of children with ADHD. J. Abnorm. Child. Psychol. 2015, 43, 1257-1269. [CrossRef]

11. Gau, S.S.F; Chang, J.P.C. Maternal parenting styles and mother-child relationship among adolescents with and without persistent attention-deficit/hyperactivity disorder. Res. Dev. Disabil. 2013, 34, 1581-1594. [CrossRef] [PubMed]

12. Gerdes, A.C.; Haack, L.M.; Schneider, B.W. Parental functioning in families of children with ADHD: Evidence for behavioral parent training and importance of clinically meaningful change. J. Atten. Disord. 2012, 16, 147-156. [CrossRef]

13. Johnston, C.; Jassy, J.S. Attention-deficit/hyperactivity disorder and oppositional/conduct problems: Links to parent-child interactions. J. Can. Acad. Child. Adolesc. Psychiatry 2007, 16, 74-79. [PubMed]

14. Lee, P.C.; Lin, K.C.; Robson, D.; Yang, H.J.; Chen, V.C.H.; Niew, W.I. Parent-child interaction of mothers with depression and their children with ADHD. Res. Dev. Disabil. 2013, 34, 656-668. [CrossRef] [PubMed]

15. Daley, D.; Van Der Oord, S.; Ferrin, M.; Cortese, S.; Danckaerts, M.; Doepfner, M.; Van den Hoofdakker, B.J.; Coghill, D.; Thompson, M.; Asherson, P.; et al. Practitioner Review: Current best practice in the use of parent training and other behavioural interventions in the treatment of children and adolescents with attention deficit hyperactivity disorder. J. Child. Psychol. Psychiatry 2018, 59, 932-947. [CrossRef] 
16. Durukan, İ.; Kara, K.; Almbaideen, M.; Karaman, D.; Gül, H. Alexithymia, depression and anxiety in parents of children with neurodevelopmental disorder: Comparative study of autistic disorder, pervasive developmental disorder not otherwise specified and attention deficit-hyperactivity disorder. Pediatr. Int. 2018, 60, 247-253. [CrossRef]

17. Wesseldijk, L.W.; Dieleman, G.C.; van Steensel, F.J.A.; Bartels, M.; Hudziak, J.J.; Lindauer, R.J.L.; Bögels, S.M.; Middeldorp, C.M. Risk factors for parental psychopathology: A study in families with children or adolescents with psychopathology. Eur. Child. Adolesc. Psychiatry 2018, 27, 1575-1584. [CrossRef]

18. Segenreich, D.; Paez, M.S.; Regalla, M.A.; Fortes, D.; Faraone, S.V.; Sergeant, J.; Mattos, P. Multilevel analysis of ADHD, anxiety and depression symptoms aggregation in families. Eur. Child. Adolesc. Psychiatry 2015, 24, 525-536. [CrossRef]

19. Harrison, C.; Sofronoff, K. ADHD and parental psychological distress: Role of demographics, child behavioral characteristics, and parental cognitions. J. Am. Acad Child. Adolesc. Psychiatry 2002, 41, 703-711. [CrossRef]

20. Barroso, N.E.; Mendez, L.; Graziano, P.A.; Bagner, D.M. Parenting stress through the lens of different clinical groups: A systematic review and meta-analysis. J. Abnorm. Child. Psychol. 2018, 46, 449-461. [CrossRef]

21. Norvilitis, J.; Scime, M.; Lee, J. Courtesy stigma in mothers of children with Attention-Deficit/Hyperactivity Disorder: A preliminary investigation. J. Atten. Disord. 2002, 6, 61-68. [CrossRef]

22. Baker, J.P.; Berenbaum, H. Emotional approach and problem-focused coping: A comparison of potentially adaptive strategies. Cogn. Emot. 2007, 21, 95-118. [CrossRef]

23. Carver, C.S.; Scheier, M.F.; Weintraub, J.K. Assessing coping strategies: A theoretically based approach. J. Pers. Soc. Psychol. 1989, 56, 267-283. [CrossRef] [PubMed]

24. Compas, B.E.; Connor-Smith, J.K.; Saltzman, H.; Thomsen, A.H.; Wadsworth, M.E. Coping with stress during childhood and adolescence: Problems, progress, and potential in theory and research. Psychol. Bull. 2001, 127, 87-127. [CrossRef] [PubMed]

25. Wilson, G.S.; Pritchard, M.E.; Revalee, B. Individual differences in adolescent health symptoms: The effects of gender and coping. J. Adolesc. 2005, 28, 369-379. [CrossRef]

26. Adams, D.; Rose, J.; Jackson, N.; Karakatsani, E.; Oliver, C. Coping Strategies in Mothers of Children with Intellectual Disabilities Showing Multiple Forms of Challenging Behaviour: Associations with Maternal Mental Health. Behav. Cogn. Psychother. 2017, 46, 257-275. [CrossRef] [PubMed]

27. Beheshti, A.; Chavanon, M.-L.; Christiansen, H. Emotion dysregulation in adults with attention deficit hyperactivity disorder: A meta-analysis. BMC Psychiatry 2020, 20, 1-11. [CrossRef] [PubMed]

28. Biederman, J.; DiSalvo, M.; Woodworth, K.Y.; Fried, R.; Uchida, M.; Biederman, I.; Spencer, T.J.; Surman, C.; Faraone, S.V. Toward operationalizing defcient emotional self-regulation in newly referred adults with ADHD: A receiver operator characteristic curve analysis. Eur. Psychiatr. 2020, 63. [CrossRef]

29. Faraone, S.V.; Rostain, A.L.; Blader, J.; Busch, B.; Childress, A.C.; Connor, D.F.; Newcorn, J.H. Practitioner Review: Emotional dysregulation in attention-deficit/hyperactivity disorder-Implications for clinical recognition and intervention. J. Child. Psychol. Psychiatry 2019, 60, 133-150. [CrossRef]

30. Gnanavel, S.; Sharma, P.; Kaushal, P.; Hussain, S. Attention defcit hyperactivity disorder and comorbidity: A review of literature. World J. Clin. Cases 2019, 7, 2420-2426. [CrossRef]

31. Ostrander, R.; Herman, K.; Sikorski, J.; Mascendaro, P.; Lambert, S. Patterns of Psychopathology in Children with ADHD: A Latent Profile Analysis. J. Clin. Child. Adolesc. Psychol. 2008, 37, 833-847. [CrossRef]

32. Reimherr, F.W.; Roesler, M.; Marchant, B.K.; Gift, T.E.; Retz, W.; Philipp-Wiegmann, F.; Reimherr, M.L. Types of Adult AttentionDeficit/Hyperactivity Disorder: A Replication Analysis. J. Clin. Psychiatry 2020, 81. [CrossRef]

33. Armstrong, D.; Lycett, K.; Hiscock, H.; Care, E.; Sciberras, E. Longitudinal Associations Between Internalizing and Externalizing Comorbidities and Functional Outcomes for Children with ADHD. Child. Psychiatry Hum. Dev. 2014, 46, 736-748. [CrossRef]

34. Bronfenbrenner, U. The Ecology of Human Development; Harvard University Press: Cambridge, MA, USA, 1979.

35. Leitch, S.; Sciberras, E.; Post, B.; Gerner, B.; Rinehart, N.; Nicholson, J.M.; Evans, S. Experience of stress in parents of children with ADHD: A qualitative study. Int. J. Qual. Stud. Health Well Being 2019, 14, 1690091. [CrossRef]

36. Theule, J.; Wiener, J.; Tannock, R.; Jenkins, J.M. Parenting Stress in Families of Children with ADHD. J. Emot. Behav. Disord. 2010, 21, 3-17. [CrossRef]

37. Zhou, T.; Wang, Y.; Yi, C. Affiliate stigma and depression in caregivers of children with Autism Spectrum Disorders in China: Effects of self-esteem, shame and family functioning. Psychiatry Res. 2018, 264, 260-265. [CrossRef]

38. Wymbs, B.T.; Pelham, W.E.; Molina, B.S.G.; Gnagy, E.M.; Wilson, T.K.; Greenhouse, J.B. Rate and predictors of divorce among parents of youths with ADHD. J. Consult. Clin. Psychol. 2008, 76, 735-744. [CrossRef] [PubMed]

39. Kiecolt-Glaser, J.K. Marriage, divorce, and the immune system. Am. Psychol. 2018, 73, 1098-1108. [CrossRef] [PubMed]

40. Cadman, T.; Eklund, H.; Howley, D.; Hayward, H.; Clarke, H.; Findon, J.; Xenitidis, K.; Murphy, D.; Asherson, P.; Glaser, K. Caregiver Burden as People With Autism Spectrum Disorder and Attention-Deficit/Hyperactivity Disorder Transition into Adolescence and Adulthood in the United Kingdom. J. Am. Acad. Child. Adolesc. Psychiatry 2012, 51, 879-888. [CrossRef] [PubMed]

41. Dada, M.U.; Okewole, N.O.; Ogun, O.C.; Bello-Mojeed, M.A. Factors associated with caregiver burden in a child and adolescent psychiatric facility in Lagos, Nigeria: A descriptive cross sectional study. BMC Pediatr. 2011, 11, 110. [CrossRef] [PubMed]

42. Wakimizu, R.; Fujioka, H.; Yoneyama, A.; Iejima, A.; Miyamoto, S. Factors associated with the empowerment of Japanese families raising a child with developmental disorders. Res. Dev. Disabil. 2011, 32, 1030-1037. [CrossRef] [PubMed] 
43. Cussen, A.; Sciberra, E.; Ukoumenne, O.G.; Efron, D. Relationship between symptoms of attention-deficit/hyperactivity disorder and family functioning: A community based study. Eur. J. Pediatr. 2012, 171, 271-280. [CrossRef]

44. Wiener, J.; Biondic, D.; Grimbos, T.; Herbert, M. Parenting Stress of Parents of Adolescents with Attention-Deficit Hyperactivity Disorder. J. Abnorm. Child. Psychol. 2016, 44, 561-574. [CrossRef]

45. Martin, J.K.; Pescosolido, B.A.; Olafsdottir, S.; McLeod, J.D. The Construction of Fear: Americans' Preferences for Social Distance from Children and Adolescents with Mental Health Problems. J. Health Soc. Behav. 2007, 48, 50-67. [CrossRef]

46. Charbonnier, E.; Caparos, S.; Trémolière, B. The role of mothers' affiliate stigma and child's symptoms on the distress of mothers with ADHD children. J. Ment. Health 2018, 28, 282-288. [CrossRef]

47. Chen, Y.-L.; Chang, C.-C.; Chen, Y.-M.; Liu, T.-L.; Hsiao, R.C.; Chou, W.-J.; Yen, C.-F. Association between affiliate stigma and depression and its moderators in caregivers of children with attention-deficit/hyperactivity disorder. J. Affect. Disord. 2021, 279, 59-65. [CrossRef]

48. Chang, C.-C.; Chen, Y.-M.; Hsiao, R.; Chou, W.-J.; Yen, C.-F. Did Affiliate Stigma Predict Affective and Behavioral Outcomes in Caregivers and Their Children with Attention-Deficit/Hyperactivity Disorder? Int. J. Environ. Res. Public Health 2021, $18,7532$. [CrossRef] [PubMed]

49. American Psychiatric Association Diagnostic and Statistical Manual of Mental Disorders, 5th ed.; American Psychiatric Association: Arlington, VA, USA, 2013. [CrossRef]

50. Chien, C.P.; Cheng, T.A. Depression in Taiwan: Epidemiological survey utilizing CES-D. Seishin Shinkeigaku Zasshi 1985, 87, 335-338. [PubMed]

51. Radloff, L.S. The CSE-D scale: A self-report depression scale for research in the general population. Appl. Psychol. Meas. 1977, 1,385-401. [CrossRef]

52. Zhang, Y.; Ting, R.Z.W.; Lam, M.H.B.; Lam, S.-P.; Yeung, R.O.; Nan, H.; Ozaki, R.; Luk, A.O.Y.; Kong, A.P.S.; Wing, Y.-K.; et al. Measuring depression with CES-D in Chinese patients with type 2 diabetes: The validity and its comparison to PHQ-9. BMC Psychiatry 2015, 15, 198. [CrossRef] [PubMed]

53. Chou, W.-P.; Yen, C.-F.; Liu, T.-L. Predicting Effects of Psychological Inflexibility/Experiential Avoidance and Stress Coping Strategies for Internet Addiction, Significant Depression, and Suicidality in College Students: A Prospective Study. Int. J. Environ. Res. Public Health 2018, 15, 788. [CrossRef] [PubMed]

54. Chen, Y.C.; Hsu, C.C.; Hsu, S.H.; Lin, C.C. A preliminary study of family Apgar index. Acta Paediatr. Sin. 1980, 21, $210-217$.

55. Smilkstein, G. The family APGAR: A proposal for a family function test and its use by physicians. J. Fam. Pract. 1978, 6, 1231-1239. [PubMed]

56. Achenbach, T.M.; Rescorla, L.A. Manual for the ASEBA School-Age Forms and Profiles; University of Vermont, Research Center for Children, Youth, and Families: Burlington, VT, USA, 2001.

57. Chen, Y.; Huang, H.L.; Chao, C.C. Achenbach System of Empirically Based Assessment; Psychological Publishing: Taipei, Taiwan, 2009.

58. Kim, H.-Y. Statistical notes for clinical researchers: Assessing normal distribution (2) using skewness and kurtosis. Restor. Dent. Endod. 2013, 38, 52-54. [CrossRef] [PubMed]

59. Senaviratna, N.A.M.R.; Cooray, T.M.J.A. Diagnosing Multicollinearity of Logistic Regression Model. Asian J. Probab. Stat. 2019, 5, 1-9. [CrossRef]

60. Chen, L.-C.; Chen, M.-H.; Hsu, J.-W.; Huang, K.-L.; Bai, Y.-M.; Chen, T.-J.; Wang, P.-W.; Pan, T.-L.; Su, T.-P. Association of parental depression with offspring attention deficit hyperactivity disorder and autism spectrum disorder: A nationwide birth cohort study. J. Affect. Disord. 2020, 277, 109-114. [CrossRef]

61. Tully, E.C.; Iacono, W.G.; McGue, M. An Adoption Study of Parental Depression as an Environmental Liability for Adolescent Depression and Childhood Disruptive Disorders. Am. J. Psychiatry 2008, 165, 1148-1154. [CrossRef]

62. Chronis, A.M.; Gamble, S.A.; Roberts, J.; Pelham, J.W.E. Cognitive-Behavioral Depression Treatment for Mothers of Children With Attention-Deficit/Hyperactivity Disorder. Behav. Ther. 2006, 37, 143-158. [CrossRef]

63. Weissman, M.M.; Pilowsky, D.J.; Wickramaratne, P.J.; Talati, A.; Wisniewski, S.; Fava, M.; Hughes, C.W.; Garber, J.; Malloy, E.; King, C.A.; et al. Remissions in Maternal Depression and Child Psychopathology. JAMA 2006, 295, 1389-1398. [CrossRef]

64. Lazarus, R.S. Coping theory and research: Past, present, and future. Psychosom. Med. 1993, 55, 234-247. [CrossRef] [PubMed]

65. Aldwin, C.M.; Revenson, T.A. Does coping help? A reexamination of the relation between coping and mental health. J. Pers. Soc. Psychol. 1987, 53, 337-348. [CrossRef]

66. Nielsen, M.B.; Knardahl, S. Coping strategies: A prospective study of patterns, stability, and relationships with psychological distress. Scand. J. Psychol. 2014, 55, 142-150. [CrossRef]

67. Achenbach, T.M.; McConaughy, S.H.; Howell, C.T. Child/adolescent behavioral and emotional problems: Implications of cross-informant correlation for situational specificity. Psychol. Bull. 1984, 101, 213-232. [CrossRef]

68. Bussing, R.; Mason, D.M.; Bell, L.; Porter, P.; Garvan, C. Adolescent Outcomes of Childhood Attention-Deficit/Hyperactivity Disorder in a Diverse Community Sample. J. Am. Acad. Child. Adolesc. Psychiatry 2010, 49, 595-605. [CrossRef]

69. Dupaul, G.J.; Mcgoey, K.E.; Eckert, T.L.; Vanbrakle, J. Preschool Children with Attention-Deficit/Hyperactivity Disorder: Impairments in Behavioral, Social, and School Functioning. J. Am. Acad. Child. Adolesc. Psychiatry 2001, 40, 508-515. [CrossRef] [PubMed]

70. Galera, C.; Melchior, M.; Chastang, J.-F.; Bouvard, M.-P.; Fombonne, E. Childhood and adolescent hyperactivity-inattention symptoms and academic achievement 8 years later: The GAZEL Youth study. Psychol. Med. 2009, 39, 1895-1906. [CrossRef] 
71. Grygiel, P.; Humenny, G.; Rẹbisz, S.; Bajcar, E.; Świtaj, P. Peer Rejection and Perceived Quality of Relations With Schoolmates Among Children With ADHD. J. Atten. Disord. 2014, 22, 738-751. [CrossRef] [PubMed]

72. Dalsgaard, S.; Leckman, J.F.; Mortensen, P.B.; Nielsen, H.; Simonsen, M. Effect of drugs on the risk of injuries in children with attention deficit hyperactivity disorder: A prospective cohort study. Lancet Psychiatry 2015, 2, 702-709. [CrossRef]

73. Hergüner, A.; Erdur, A.E.; Başçiftçi, F.A.; Herguner, S. Attention-deficit/hyperactivity disorder symptoms in children with traumatic dental injuries. Dent. Traumatol. 2015, 31, 140-143. [CrossRef]

74. Chen, V.C.-H.; Chan, H.-L.; Wu, S.-I.; Lee, M.; Lu, M.-L.; Liang, H.-Y.; Dewey, M.E.; Stewart, R.; Lee, C.T.-C. AttentionDeficit/Hyperactivity Disorder and Mortality Risk in Taiwan. JAMA Netw. Open 2019, 2, e198714. [CrossRef]

75. Gokcen, C.; Coşkun, Ş.; Kütük, M. Özlem Comparison of Depression and Burnout Levels of Mothers of Children with AttentionDeficit Hyperactivity Disorder before and After Treatment. J. Child. Adolesc. Psychopharmacol. 2018, 28, 350-353. [CrossRef]

76. Kim, Y.; Kim, B.; Chang, J.-S.; Kim, B.-N.; Cho, S.-C.; Hwang, J.-W. Parental quality of life and depressive mood following methylphenidate treatment of children with attention-deficit hyperactivity disorder. Psychiatry Clin. Neurosci. 2014, 68, 506-514. [CrossRef] [PubMed]

77. Schatz, D.B.; Rostain, A.L. ADHD with Comorbid Anxiety. J. Atten. Disord. 2006, 10, 141-149. [CrossRef] [PubMed]

78. Blackman, G.L.; Ostrander, R.; Herman, K.C. Children with ADHD and Depression: A Multisource, Multimethod Assessment of Clinical, Social, and Academic Functioning. J. Atten. Disord. 2005, 8, 195-207. [CrossRef] [PubMed]

79. March, J.S.; Swanson, J.M.; Arnold, L.E.; Hoza, B.; Conners, C.K.; Hinshaw, S.P.; Hechtman, L.; Kraemer, H.C.; Greenhill, L.L.; Abikoff, H.B.; et al. Anxiety as a Predictor and Outcome Variable in the Multimodal Treatment Study of Children with ADHD (MTA). J. Abnorm. Child. Psychol. 2000, 28, 527-541. [CrossRef] [PubMed]

80. Tannock, R.; Ickowicz, A.; Schachar, R. Differential Effects of Methylphenidate on Working Memory in ADHD Children with and without Comorbid Anxiety. J. Am. Acad. Child. Adolesc. Psychiatry 1995, 34, 886-896. [CrossRef] [PubMed] 